\title{
Retrospective Study of the Prevalence of Dry Socket in Patients with Mandibular Third Molar Extraction
}

\author{
Meenapriya Murthi ${ }^{1}$, Pradeep Dhasarathan ${ }^{2}$, Deepika Rajendran ${ }^{3}$
}

\begin{abstract}
Aim: The aim of this retrospective study is to assess the demographic details, mode of extraction, and prevalence of dry socket in patients with mandibular third molar extraction.

Materials and methods: Patients who had undergone mandibular third molar (impacted/nonimpacted) extraction were included in this study. The case sheets were obtained from Saveetha Dental College and Hospitals. The information retrieved from the Saveetha Dental College and Hospitals dental information archiving software (DIAS) system included patient's age, gender, systemic disease (diabetes), teeth no. and the mode of extraction of teeth (transalveolar, surgical extraction of impacted teeth, extraction), and the postoperative complications (dry socket) associated. The data included for this study were from June 2019 to March 2020 and tabulated. The statistical test was carried out through SPSS and the Pearson's Chi-square test was performed.

Results: Total 691 patients who had undergone mandibular third molar extraction during June 2019 to March 2020 were included in this study. Out of 691 patients, $53.91 \%$ were males and $46.09 \%$ were females. The higher prevalence of age groups of 26-35 (36.06\%) was noted. Total $94.5 \%$ of the patients were diabetic and $5.5 \%$ were nondiabetic. The most number of treatments done is through surgical extraction of impacted teeth (surgical exposure of flap and tooth) (48.48\%), followed by extraction (forceps extraction) (42.55\%) and transalveolar extraction (removing section of tooth, open sectioning) (8.97\%). The prevalence of dry socket was $4.05 \%$, and $95.95 \%$ of the patients did not experience dry socket. There was higher prevalence of dry socket in nondiabetic patients (3.62\%) than diabetic patients (0.43\%).

Conclusion: The dry socket was most commonly associated with males and during normal extraction (i.e., without surgical exposure of flap and tooth). The dry socket remains as the common postoperative complication.

Clinical significance: The study observed that the extraction (through forceps) procedure leads to an increased incidence of dry socket. Hence, this signifies the importance of postoperative instructions to be followed irrespective of the type of extraction.

Keywords: Diabetic, Dry socket, Mandibular third molar, Nondiabetic, Wound healing.

World Journal of Dentistry (2020): 10.5005/jp-journals-10015-1766
\end{abstract}

\section{INTRODUCTION}

Dry socket, otherwise known as the alveolar osteitis or fibrinolytic osteitis, is a global phenomenon. Crawford in 1896 first coined the term "dry socket."1 Dry socket refers to the acute inflammation of the alveolar bone surrounding the extracted tooth socket. Patients experience severe pain and discomfort post extraction. This is presented clinically with the features of clot destruction, followed by food debris accumulation inside the extracted tooth socket. Other features include mild swelling, redness of gingiva, bone exposure, tenderness on palpation, and halitosis. ${ }^{2}$

The etiology of dry socket is not well known and studied. Many local and systemic factors may contribute to the etiology of dry socket. $^{3}$ The local factors include traumatic extractions and the level of difficulty in extracting, decreased vascularity, and increased bone density. The incidence of dry socket is more common in the mandibular third molar extraction. Systemic factors such as diabetes mellitus may contribute to the incidence of dry socket. This is due to the altered healing in diabetic patients. Delayed healing is reported as the well-known complication of oral surgeries in diabetic patients. ${ }^{4}$

Diabetes mellitus has become an increasing health problem worldwide. This is characterized by the abnormal metabolism of proteins and carbohydrates leading to increased blood sugar level. This resultant hyperglycemia can contribute to microvascular complications. Diabetic patients are more susceptible to oral and

\begin{abstract}
1,2Department of Oral and Maxillofacial Surgery, Saveetha Dental College, Saveetha Institute of Medical and Technical Sciences, Saveetha University, Chennai, Tamil Nadu, India

${ }^{3}$ Department of Oral Medicine and Radiology, Saveetha Dental College, Saveetha Institute of Medical and Technical Sciences, Saveetha University, Chennai, Tamil Nadu, India

Corresponding Author: Pradeep Dhasarathan, Department of Oral and Maxillofacial Surgery, Saveetha Dental College, Saveetha Institute of Medical and Technical Sciences, Saveetha University, Chennai, Tamil Nadu, India, Phone: +91 9789936383, e-mail: pradeep@saveetha.com How to cite this article: Murthi M, Dhasarathan P, Rajendran D. Retrospective Study of the Prevalence of Dry Socket in Patients with Mandibular Third Molar Extraction. World J Dent 2020;11(5):425-430.

Source of support: Saveetha Dental College and Hospital

Conflict of interest: None
\end{abstract}

dental problems and complications including the various oral soft tissue injuries and inflammatory conditions. ${ }^{5}$

Previous studies conducted on the factors affecting the incidence of dry socket revealed that the experience of the operator, root fractures, periodontal disease, and posterior teeth are the risk factors for the development of dry socket or alveolar osteitis. ${ }^{6}$ The post-extraction socket changes in diabetic patients revealed that apart from the local factors, the post-extraction socket healing could be delayed in the diabetic patients. ${ }^{7}$ The previous study 
conducted on the incidence of dry socket in Jordan reveals that there was increased prevalence of dry socket in smoking and surgical trauma cases. ${ }^{8}$

The challenges faced by previous studies include that there were not many studies conducted on the etiology of dry socket. Thus, the etiology of dry socket remains unknown and not well understood. The importance of postoperative instructions to be followed by the patients after extraction was not highlighted in the previous literature.

Previously, the Department of Oral and Maxillofacial surgery of Saveetha Dental College and Hospitals has published extensive research on various aspects of the oral and maxillofacial region. This vast research experience has guided us for further studies. ${ }^{9-23}$ Therefore, the aim of this retrospective study is to assess the demographic details, mode of extraction, and prevalence of dry socket in patients on mandibular third molar extraction.

\section{Materials and Methods}

The study was conducted with the approval of the institutional ethics committee of Saveetha Dental College and Hospitals [SDC/ SIHEC/2020/DIASDATA/0619-0320].

This research was conducted among the patients of Saveetha Dental College and Hospitals. Data were collected and reviewed from the institutional dental information archiving software (DIAS) system. Total 691 cases were reported between June 2019 and March 2020 for the mandibular third molar extraction (impacted/ nonimpacted). The study population considered was evaluated for the presence of dry socket and also for the presence of diabetes mellitus.

\section{Inclusion Criteria}

- Patients undergoing extraction of mandibular third molar (impacted/nonimpacted)

- Dry socket

- Demographic details of the patient

- Mode of extraction [extraction (forceps extraction)/transalveolar extraction (sectioning of tooth followed by removal), surgical extraction of impacted teeth (surgical exposure of flap and tooth)].

\section{Exclusion Criteria}

- Any teeth other than mandibular third molar extraction

- Postoperative complications other than dry socket were excluded.

Since this study was conducted in a university setting, retrieval of data was easier. This data were collected within the specific time period. This study focuses only on the mandibular third molar exodontia. This study focuses only on a certain population who visited the dental college.

Overall, 691 case sheets were reviewed for the incidence of dry socket. This was cross-verified with the clinical photographs for errors. The study population was clearly identified and the random sampling technique was followed. Hence, the sampling bias was minimized.

Data were collected and tabulated in an Excel sheet. Incomplete data were excluded. The statistical analysis using SPSS by IBM was done through the Pearson's Chi-square test. The independent variables in this present study were systemic diseases (diabetic patients), quadrant associated, age, and treatment modes, and the dependent variables include the dry socket.

\section{Results}

Out of 691 cases, where mandibular third molar extraction was performed, the following results were seen. Out of 691 patients, $53.91 \%$ were males and $46.09 \%$ were females. Therefore, the prevalence of dry socket was greater in males than the females comparatively. The distribution of age groups was done and there was a higher prevalence of age groups of 26-35 (36.06\%). The age distribution is illustrated in Figure 1.

The study population considered for dry socket was also evaluated for the presence of diabetes mellitus. Total 38 of the patients were diabetic and 653 were nondiabetic (Fig. 2). The most number of treatments done is through surgical extraction of impacted teeth (surgical exposure of flap and tooth) (48.48\%), followed by extraction (forceps extraction) (42.55\%) and transalveolar extraction (sectioning of tooth, open extraction) (8.97\%). The prevalence of dry socket was $4.05 \%$, and $95.95 \%$ of the patients did not experience dry socket. This shows the lower prevalence of dry socket in the study population (Fig. 3).

The age of the patient was correlated with the prevalence of dry socket. The most common age group associated with prevalence of dry socket was 26-35 (2.19\%). This correlation was not statistically significant (Fig. 4). The correlation of gender of the patient with the prevalence of dry socket showed that there was higher prevalence of dry socket in males (2.61\%) than the females. This was not statistically significant (Fig. 5).

The higher prevalence of dry socket was associated with extraction (forceps extraction) (2.03\%) than the surgical exposure (surgical exposure of flap and tooth) and transalveolar extractions (open extraction, sectioning, and removal). However, this was not significant (Fig. 6). The teeth which are associated with dry socket frequently were $38(2.17 \%)$ than 48 . However, this was not statistically significant (Fig. 7). The number of diabetic and nondiabetic patients with dry socket were 3 and 25 patients, respectively (Fig. 8).

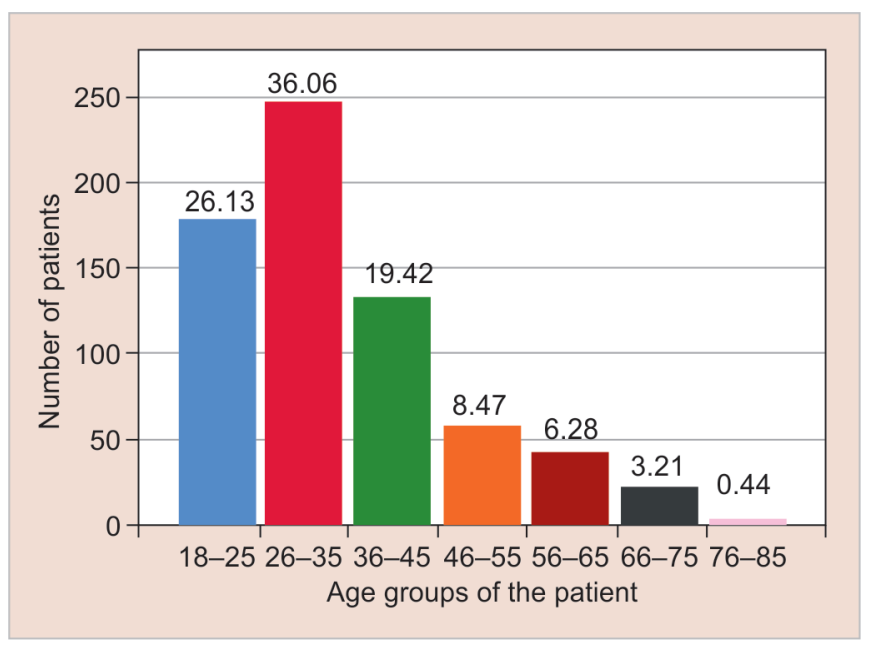

Fig. 1: Bar graph showing different age groups of the study population. The $x$-axis represents the age groups of the patient involved in this study and the $y$-axis shows the number of patients. This graph shows higher prevalence of age groups of $26-35$ (36.06\%) 


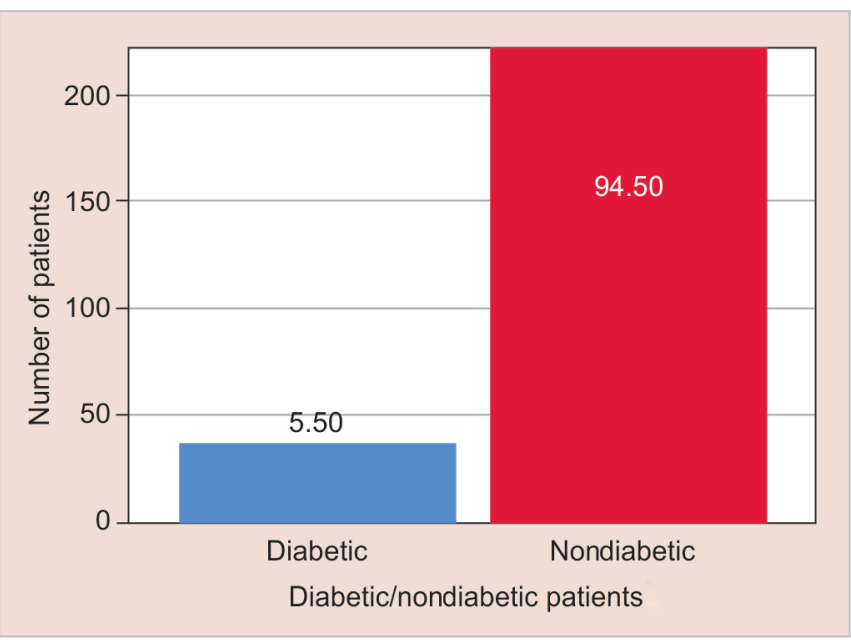

Fig. 2: Bar graph showing the study population, which involved diabetic vs nondiabetic patients. (Blue graph shows diabetic patients and red nondiabetic patients.) The graph shows a higher population of nondiabetic patients $(94.50 \%)$ than that of the diabetic patients $(5.50 \%)$

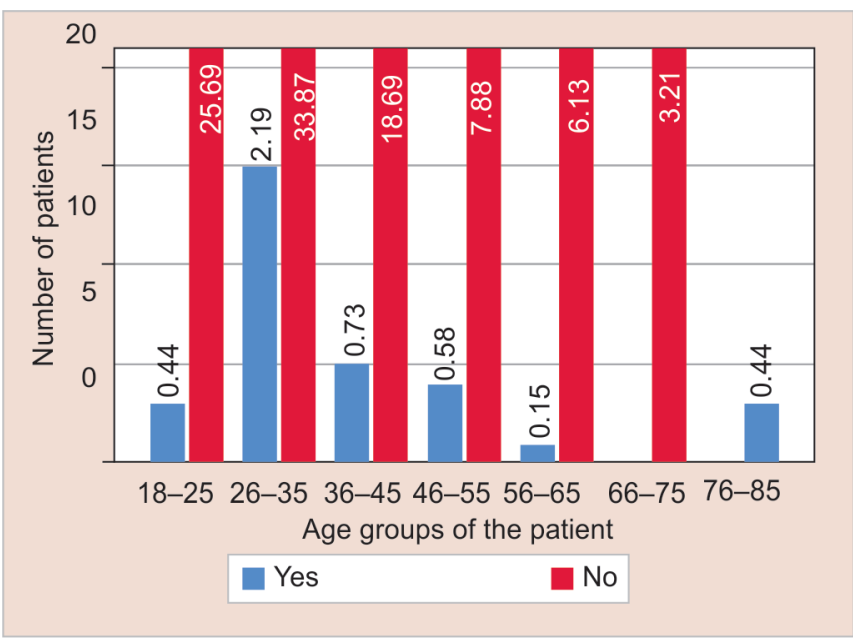

Fig. 4: Bar graph showing age groups (blue) associated with the incidence of dry socket in diabetic as well as nondiabetic patients. Age group ( $x$-axis), number of patients ( $y$-axis). This graph shows higher prevalence of dry socket in patients of 26-35 age group (2.19\%). However, this correlation was statistically not significant (Pearson's Chisquare test; $p$ value $=0.257 ; p>0.05$-not significant)

\section{Discussion}

In this study, the age groups most frequently associated with dry socket were 26-35 years. The supporting studies for this study would be the incidence of dry socket observed in Iranian population. The age group that showed the highest incidence of dry socket is $23-26 .^{24}$ Previous studies in contrast with this study were dry socket prevalence and incidence study conducted by Ali Hussain et al. This study revealed that the most common age group involved in dry socket prevalence was below 18 years. ${ }^{25}$ This study is in accordance with the consensus that the incidence of dry socket prevails equally among all the age groups from 18 to 60 years.

The gender distribution in this study reveals higher prevalence of dry socket incidence among males than the females. The supporting studies for this study, which had higher prevalence of

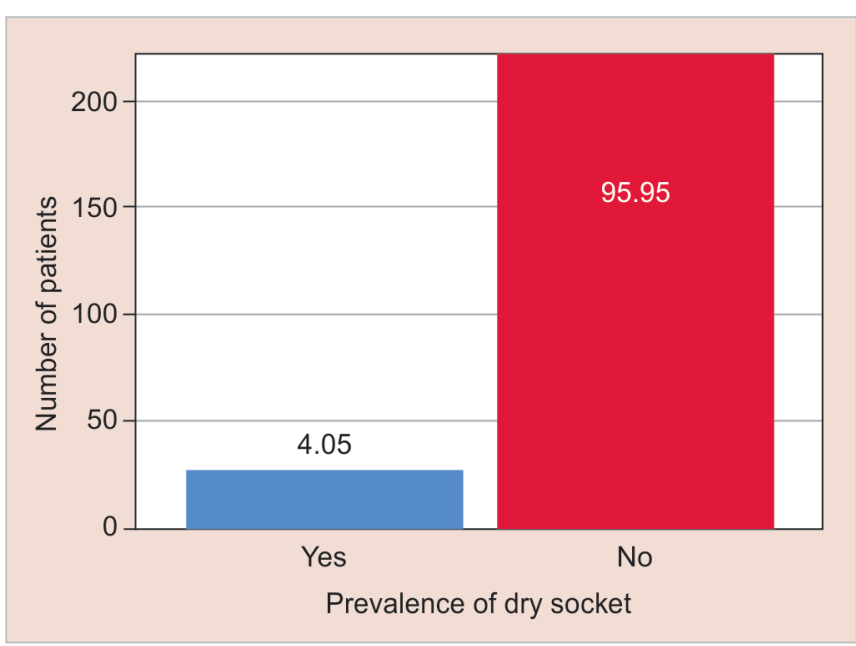

Fig. 3: Bar graph showing the prevalence of dry socket in the study population. (Blue graph depicts prevalence, red-no dry socket.) The graph shows a less prevalence of dry socket (4.05\%) among the study population

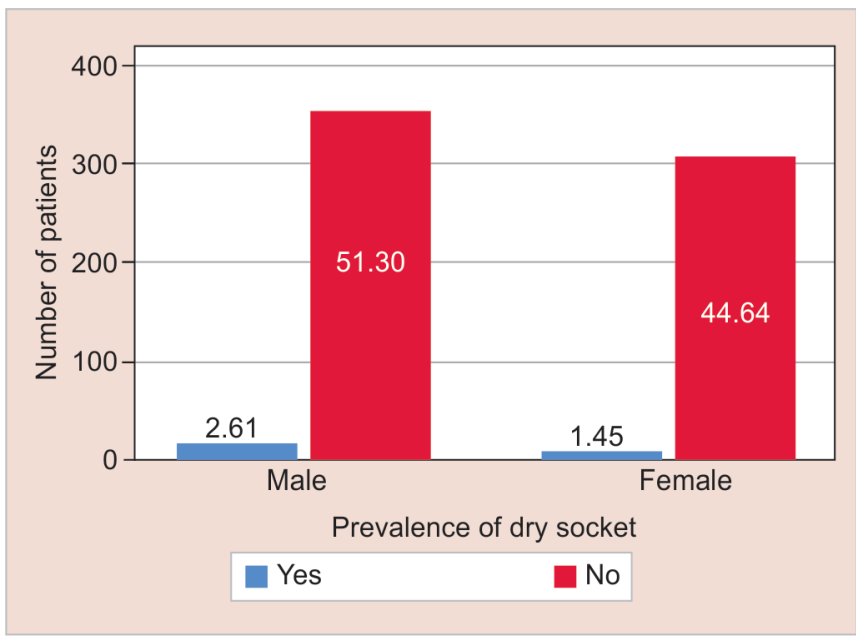

Fig. 5: Bar graph showing gender distribution ( $x$-axis) associated with the prevalence of dry socket ( $y$-axis). Dry socket (blue), no dry socket (red). The prevalence of dry socket is more in males (2.61\%) than females $(1.45 \%)$. However, this correlation was statistically not significant (Pearson's Chi-square test; $p$ value $=0.520 ; p>0.05$-not significant

dry socket in males, were found in a study conducted by Alsaleh et al. ${ }^{26}$ The study revealed higher prevalence of dry socket in males (60.7\%) than females (39.3\%). The previous study conducted by Marcelo Carlos et al. revealed equal prevalence of dry socket among males and the females. However, the study conducted by Abu Younis et al. reported no statistical association between development of dry socket and the patient's gender. ${ }^{27}$

In this study, there is higher prevalence of surgical extraction of impacted teeth than the extraction and transalveolar extraction. But the prevalence of dry socket was more in extraction. The study conducted previously by Murad et al. showed the higher prevalence of dry socket in surgically extracted teeth than the nonsurgically extracted teeth. ${ }^{28,29}$ Surgical extraction includes the flap elevation with bone cutting. There were no contradictory studies with this study. The consensus is that there is a higher prevalence of dry 


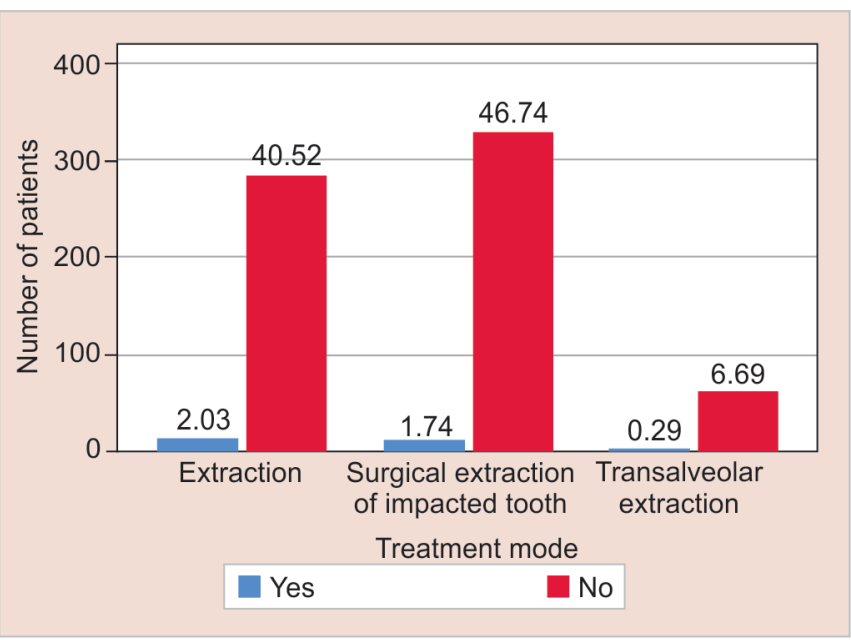

Fig. 6: Bar graph showing various treatment modes ( $x$-axis) associated with prevalence of dry socket (y-axis). Dry socket (blue), no dry socket (red). This graph reveals higher prevalence of dry socket in extraction cases $(2.03 \%)$ than the surgical extraction (1.74\%) and transalveolar extraction (0.29\%). However, this correlation was statistically not significant (Pearson's Chi-square test; $p$ value $=0.712 ; p>0.05-$ not significant)

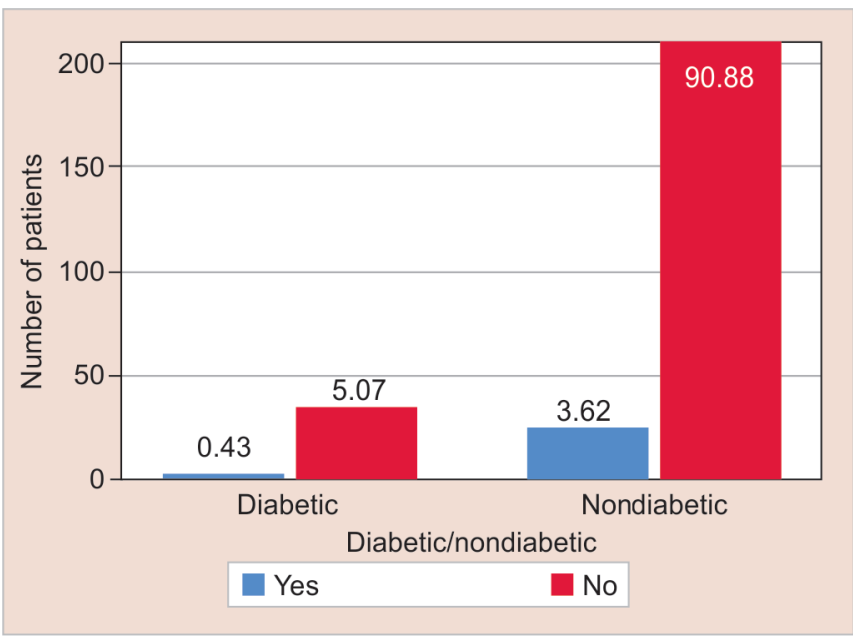

Fig. 8: Bar graph showing the study population—diabetic/nondiabetic patients ( $x$-axis) associated with the incidence of dry socket ( $y$-axis). Dry socket (blue), no dry socket (red). The graph shows higher prevalence of dry socket in nondiabetic patients (3.62\%) than diabetic patients ( $0.43 \%$ ). However, this correlation was statistically not significant (Pearson's Chisquare test; $p$ value $=0.217 ; p>0.05$ —not significant $]$

socket in nonsurgically extracted teeth than the surgically extracted teeth.

The incidence of dry socket was greater in the lower left mandibular third molar [38] than the lower right mandibular third molar [48] according to this study. The previous literature supporting this study reported higher prevalence of dry socket in mandibular teeth, especially the molars following extraction. ${ }^{30}$ There were no contradictory studies associated with this study. The consensus is that there is higher prevalence of dry socket in mandibular molar extraction.

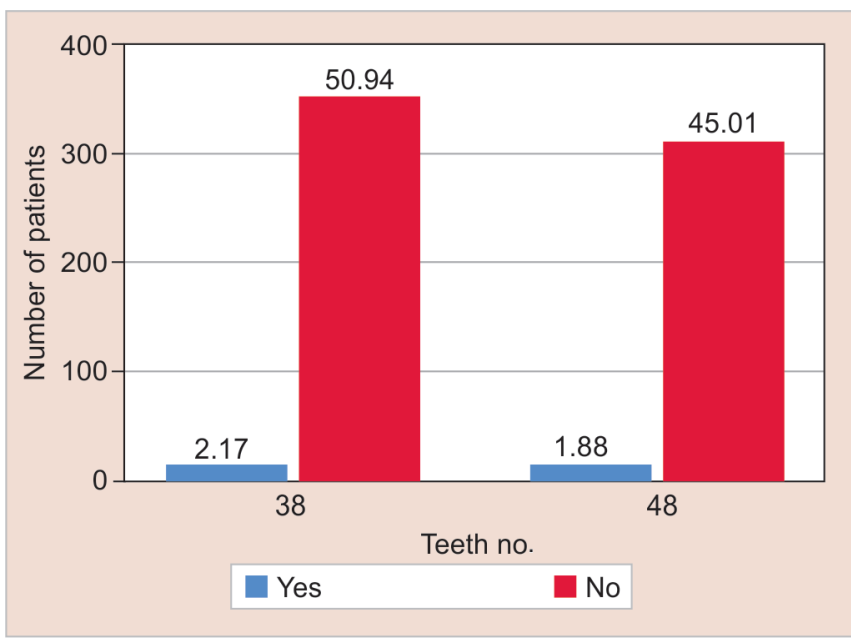

Fig. 7: Bar graph showing the teeth no. ( $x$-axis) associated with the incidence of dry socket ( $y$-axis). Dry socket (blue), no dry socket (red). The graph shows higher prevalence of dry socket in 38 (2.17\%) than $48(47.83 \%)$. However, this correlation was statistically not significant (Pearson's Chi-square test; $p$ value $=0.960 ; p>0.05$ —not significant]

The participants who were diabetic with dry socket were 3 patients and the participants who were without dry socket development were 35 patients. The most common mode of extraction for diabetic patients with dry sockets was surgical extraction of impacted teeth and those without dry socket was forceps extraction. The patients who were nondiabetic with dry socket were 25 patients and those without dry socket involvement were 628 patients. The most common mode of extraction for nondiabetic patients with dry socket was surgical extraction of impacted teeth and forceps extraction. The most common mode of extraction for nondiabetic patients without dry socket involvement was extraction. The age group commonly associated with diabetic patients was 46-65 years. The age group most commonly associated with nondiabetic patients was 26-35 years.

Therefore, according to this study, systemic factors are not the significant factors in the role of dry socket prevalence. This shows that systemic factors alters the healing of dry socket and it is not the contributing factor for the incidence of dry socket. The studies in agreement with this is AlHindi et al., which report dry socket following teeth extraction and its management strategies. ${ }^{31,32}$ The contradictory studies associated with this study report other systemic diseases associated with incidence of diabetes mellitus. ${ }^{33,34}$

\section{Limitations}

This study covered only limited populations. The patients who reported to Saveetha Dental College and Hospitals were only considered. The postoperative complications other than dry socket were not considered. This study did not include all the teeth that underwent extraction. Rather, it focused only on the mandibular third molar extraction.

\section{Future Studies}

Future studies should be conducted to report the incidence of dry socket associated with extractions in other parts of the population. The inclusion of all the teeth that underwent extractions should be considered. 


\section{Conclusion}

Within the limits of this study, the prevalence of dry socket was higher in males than the females. The common age group associated with the prevalence of dry socket was 26-35. The dry socket was more prevalent in the mandibular lower left third molar. The clinical significance of this study reported the higher prevalence of dry socket in patients who had undergone normal extraction, where the flap and the tooth were not exposed surgically. The diabetic patients with dry socket were less than the diabetic patients without dry socket development. Therefore, this study concludes that the systemic factors are not the only factors in determining the prevalence of dry socket.

\section{Acknowledgments}

The authors would like to acknowledge the Chancellor, Director of Academics, Principal, and the Associate Dean of Research, Vice Chancellor, Saveetha University. The authors would like to acknowledge the HOD and their professors, readers, lecturers, and their fellow postgraduates, Department of Oral and Maxillofacial Surgery, Saveetha University.

\section{References}

1. Chandran S, Alaguvelrajan M, Karthikeyan A, et al. Incidence of dry socket in South Chennai population: a retrospective study. J Int Oral Health 8(1):119-122.

2. Akinbami BO, Godspower T. Dry socket: incidence, clinical features, and predisposing factors. Int J Dent 2014;2014:796102. DOI: 10.1155/2014/796102.

3. Jallo L, Fadhul H, AlMoosa M, et al. Incidence of alveolar osteitis in diabetic patients attending university hospital. Itali J Dent Med 2019;4:3.

4. Khan A, Khan MA, Nasir A. Comparison of healing of the extraction socket in diabetic vs non-diabetic patients. Cell 2017;321:9093036.

5. Akhavan Karbassi MH, Salehi R, Kheirollahi K, et al. The relationship between socket blood sugar and post-extraction complications in type II diabetic and non-diabetic patients. Iran J Diab Obes 2015;7(1):12-19.

6. Parthasarathi K, Smith A, Chandu A. Factors affecting incidence of dry socket: a prospective community-based study. J Oral Maxillofac Surg 2011;69(7):1880-1884. DOI: 10.1016/j.joms.2010.11.006.

7. Zhang S, Wang S, Wei H, et al. Post-extraction socket changes in diabetic patients-a retrospective study. Int J Clin Exp Med 2016;9(7):14077-14086.

8. Nusair YM, Younis MHA. Prevalence, clinical picture, and risk factors of dry socket in a Jordanian Dental Teaching Center. J Contemp Dent Pract 2007;8(3):53-63. DOI: 10.5005/jcdp-8-3-53.

9. Jesudasan JS, Wahab PUA, Sekhar MRM. Effectiveness of $0.2 \%$ chlorhexidine gel and a eugenol-based paste on postoperative alveolar osteitis in patients having third molars extracted: a randomised controlled clinical trial. Br J Oral Maxillofac Surg 2015;53(9):826-830. DOI: 10.1016/j.bjoms.2015.06.022.

10. Christabel A, Anantanarayanan P, Subash P, et al. Comparison of pterygomaxillary dysjunction with tuberosity separation in isolated Le Fort I osteotomies: a prospective, multi-centre, triple-blind, randomized controlled trial. Int J Oral Maxillofac Surg 2016;45(2):180185. DOI: 10.1016/j.ijom.2015.07.021.

11. Vijayakumar Jain S, Muthusekhar MR, Baig MF, et al. Evaluation of three-dimensional changes in pharyngeal airway following isolated Lefort one osteotomy for the correction of vertical maxillary excess: a prospective study. J Maxillofac Oral Surg 2019;18(1):139-146. DOI: 10.1007/s12663-018-1113-4.
12. Abhinav RP, Selvarasu K, Maheswari GU, et al. The patterns and etiology of maxillofacial trauma in South India. Ann Maxillofac Surg 2019;9(1):114-117. DOI: 10.4103/ams.ams_233_18.

13. Santhosh Kumar MP. Relationship between dental anxiety and pain experience during dental extractions. Asian J Pharmaceut Clin Res 2017(3):458-461. DOI: 10.22159/ajpcr.2017.v10i3.16518.

14. Santhosh Kumar MP, Rahman R. Knowledge, awareness, and practices regarding biomedical waste management among undergraduate dental students. Asian J Pharmaceut Clin Res 2017(8):341-345. DOI: 10.22159/ajpcr.2017.v10i8.19101.

15. Marimuthu M, Andiappan M, Wahab A, et al. Canonical Wnt pathway gene expression and their clinical correlation in oral squamous cell carcinoma. Indian J Dent Res 2018;29(3):291-297. DOI: 10.4103/ijdr. IJDR_375_17.

16. Patil SB, Durairaj D, Suresh Kumar G, et al. Comparison of extended nasolabial flap versus buccal fat pad graft in the surgical management of oral submucous fibrosis: a prospective pilot study. J Maxillofac Oral Surg 2017;16(3):312-321. DOI: 10.1007/s12663-016-0975-6.

17. Packiri $S$, Gurunathan $D$, Selvarasu K. Management of paediatric oral ranula: a systematic review. J Clin Diagn Res 2017;11(9):ZE06-ZE09. DOI: 10.7860/JCDR/2017/28498.10622.

18. Rao TD, Santhosh Kumar MP. Analgesic efficacy of paracetamol vs ketorolac after dental extractions. Res J Pharm Technol 2018;11(8):3375-3379. DOI: 10.5958/0974-360X.2018.00621.2.

19. Sweta VR, Abhinav RP, Ramesh A. Role of virtual reality in pain perception of patients following the administration of local anesthesia. Ann Maxillofac Surg 2019;9(1):110-113. DOI: 10.4103/ams. ams_263_18.

20. Santhosh Kumar MP, Sneha S. Knowledge and awareness regarding antibiotic prophylaxis for infective endocarditis among undergraduate dental students. Asian J Pharmaceut Clin Res 2016. 154-159. DOI: 10.22159/ajpcr.2016.v9s2.13405.

21. Rahman R, Santhosh Kumar MP. Knowledge, attitude and awareness of dental undergraduate students regarding hiv/aids patients. Asian J Pharmaceut Clin Res 2017;6(11):175-180.

22. Santhosh Kumar MP. The emerging role of botulinum toxin in the treatment of orofacial disorders: literature update. Asian J Pharmaceut Clin Res 2017(9):21-29. DOI: 10.22159/ajpcr.2017. v10i9.16914.

23. Patturaja K, Pradeep D. Awareness of basic dental procedure among general population. Res J Pharm Technol 2016;9(9):1349. DOI: 10.5958/0974-360X.2016.00258.4.

24. Eshghpour M, Nejat AH. Dry socket following surgical removal of impacted third molar in an Iranian population: incidence and risk factors. Niger J Clin Pract 2013;16(4):496-500. DOI: 10.4103/11193077.116897.

25. Khan AH. Prevalence and association of dry socket in oral health and dental management. Oral Health Dent Manag 2017;16(4):1-6.

26. Alsaleh MK, Alajlan SS, Alateeq NF, et al. Alveolar osteitis: patient's compliance with post-extraction instructions following permanent teeth extraction. J Contemp Dent Pract 2018;19(12):1517-1524. DOI: 10.5005/jp-journals-10024-2459.

27. Bortoluzzi MC, Manfro R, De Déa BE, et al. Incidence of dry socket, alveolar infection, and postoperative pain following the extraction of erupted teeth. J Contemp Dent Pract 2010;11(1):E033-E040. DOI: 10.5005/jcdp-11-1-33.

28. Murad N, Qayyum Z, Fatima B, et al. Serious post extraction complaint. Pakistan Oral Dent J 2014;34(3):37.

29. Vettori E, Costantinides F, Nicolin V, et al. Factors influencing the onset of intra- and post- operative complications following tooth exodontia: retrospective survey on 1701 patients. Antibiotics (Basel) 2019;8(4):264.

30. Mudali V, Mahomed O. Incidence and predisposing factors for dry socket following extraction of permanent teeth at a regional hospital in Kwa-Zulu Natal. SADJ 2016;71(4):166-169. 
31. AlHindi M. Dry socket following teeth extraction: effect of excessive socket saline irrigation. J Oral Health Dent Sci 2017;1: 105.

32. Nakaue K, Aoki K, Ueyama Y, et al. Extraction of lower third molars: risk indication for postoperative complications. J Oral Maxillofac Surg 2014;72(9):e79. DOI: 10.1016/j.joms.2014. 06.138 .
33. Gazal G. Management of an emergency tooth extraction in diabetic patients on the dental chair. Saudi Dent J 2020;32(1):1-6. DOI: 10.1016/j.sdentj.2019.07.004.

34. Power DJ, Sambrook PJ, Goss AN. The healing of dental extraction sockets in insulin-dependent diabetic patients: a prospective controlled observational study. Aust Dent J 2019;64(1):111-116. DOI: 10.1111/adj.12669. 